\title{
Abrasive Wear Behaviour of Fe-30Cr-3.6C Overlays Deposited on Mild Steel
}

\author{
Tarun SHARMA, Saurabh MARIA and D. K. DWIVEDI ${ }^{1)}$ \\ Mechanical Engineering Department, National Institute of Technology, Hamirpur, H.P., India, 177005. \\ 1) Mechanical \& Industrial Engineering Department, Indian Institute of Technology Roorkee, Roorkee, U. A., India, 247667. \\ E-mail: dkd04fme@iitr.ernet.in
}

(Received on October 18, 2004; accepted on June 1, 2005)

\begin{abstract}
This paper describes the influence of sliding wear conditions and post weld heat treatment on abrasive wear resistance of iron base hardfacing overlays (Fe-30 Cr-3.6C) deposited on mild steel. Overlays were deposited by a shielded metal arc (SMA) welding process on mild steel using a commercially available hardfacing electrode (Sugar-Arc) of $4.0 \mathrm{~mm}$ in diameter. Overlays were deposited using a welding current of $250 \mathrm{~A}$ (DCEN) and welding speed of $15 \mathrm{~cm} / \mathrm{min}$. The abrasive wear resistance of overlays in as-welded and heattreated condition was tested using a pin on disc type wear testing machine against a 320 grade SiC abrasive paper at different normal loads (1-4N). Optical microscopy was used to study the microstructure of overlays. Scanning electron microscopy (SEM) wear surfaces was carried out to analyze the wear mechanism. Variation in the hardness across the coating substrate interface of was observed. Post weld heat treatment improved the abrasive wear resistance.
\end{abstract}

KEY WORDS: Fe-Cr-C; chromium carbide; heat treatment; microstructure; abrasive wear; micro-cutting; hardness; dilution; overlays.

\section{Introduction}

There is a demand for the reclamation of worn-out metal parts through out the world. The application of a hard, wear resistant surface layer of various wear resistant metals and alloys on metallic substrate by welding is one of the most widely used technologies for reclamation. ${ }^{1,2)}$ But without carefully controlled applications of the overlays, welding causes the penetration of weld metal into the base metal, which in turn results in poor quality control of the coating composition. $^{3-5)}$ The influence of compositions of coating, ${ }^{6-11)}$ heat treatment, ${ }^{9)}$ welding parameters, ${ }^{3)}$ sliding conditions $^{10,12-15)}$ and microstructure ${ }^{11)}$ on the abrasive wear behaviour of $\mathrm{Fe}-\mathrm{Cr}-\mathrm{C}$ base hardfacing alloy coatings have been discussed previously.

The presence of inter-metallic compounds such as $(\mathrm{Cr}, \mathrm{Fe})_{7} \mathrm{C}_{3}$ in austenite matrix hardens the overlays without the sacrifice of toughness. ${ }^{15)}$ Dasgupta et al. ${ }^{12,13)}$ studied the effect of $\mathrm{Cr}$ percentage on abrasive wear behaviour of $\mathrm{Fe}-\mathrm{Cr}-\mathrm{C}$ coating and found that wear resistance improved only if $\mathrm{Cr} \%$ is more than 3 . Below that it does not affect the wear rate. In the present study, iron base hardfacing electrodes were used to develop the overlays subsequently these overlays were heat treated. Attempts have been made to study the effect of sliding conditions (sliding distance, normal load) and heat treatment on the microstructure and wear behaviour of iron-base high chromium and high carbon overlays.

\section{Experimental Procedure}

\subsection{Hardfacing}

An iron-base hardfacing electrode was used for overlaying the mild steel by shielded metal arc (SMA) welding. Chemical compositions of the mild steel and hardfacing electrodes are shown in Table 1. Overlays were produced by SMA welding (DCEN) using $250 \mathrm{~A}$ welding current at constant wedling speed of $15 \mathrm{~cm} / \mathrm{min}$. Post weld heat treatment of overlays was carried out at constant temperature of $300^{\circ} \mathrm{C}$ for $1 \mathrm{~h}$ in a muffle furnace. A transverse section of the hardfaced steel was metallographically polished using conventional metallographic polishing technique and

Table 1. Chemical composition (wt $\%$ ) of base metal and electrode used for hardfacing.

\begin{tabular}{|l|l|l|}
\hline $\begin{array}{l}\text { Element } \\
(\text { wt. \%) }\end{array}$ & $\begin{array}{l}\text { Mild steel } \\
\text { substrate }\end{array}$ & $\begin{array}{l}\text { Hardfacing } \\
\text { electrode }\end{array}$ \\
\hline $\mathrm{C}$ & 0.2 & 3.6 \\
\hline $\mathrm{Si}$ & 1.2 & 0.4 \\
\hline $\mathrm{Mn}$ & 0.7 & 0.8 \\
\hline $\mathrm{S}$ & 0.4 & - \\
\hline $\mathrm{P}$ & 0.05 & - \\
\hline $\mathrm{Cr}$ & - & 30.0 \\
\hline $\mathrm{V}$ & - & 0.1 \\
\hline $\mathrm{Mo}$ & - & 0.2 \\
\hline $\mathrm{Fe}$ & Balance & Balance \\
\hline
\end{tabular}


etched with $0.1 \%$ Nital solution. A Reichert Jung (MEF-3) optical microscope was used to examine the microstructure of as welded and heat treated specimen. A scanning electron microscope (Leo-435-VP-England) was used to study the wear mechanism of worn out surfaces. A Rockwell hardness test (HRC) was performed to measure the hardness of coating, interface and base metal.

\subsection{Wear Test}

Two body abrasive wear test was carried out using the pin on disc type wear testing machine (Model: TR-20L, DUCOM). Schematic diagram of wear testing machine is shown in Fig. 1. Rectangular-shaped specimens having $6 \mathrm{~mm}$ square cross section and $20 \mathrm{~mm}$ length were cut from the hardfaced steel. The samples were then ground to remove the sharp edges from wear pins before the sliding tests. Polishing paper (320 grade) embedded with $\mathrm{SiC}$ particles was used as abrasive medium. The specimen was fixed with a locking arrangement against the abrasive medium. Load was applied on the specimen by a cantilever method. Hardfaced end was held at different normal loads (1-4N) against the disc carrying abrasive medium and disc was rotated at $400 \mathrm{rpm}$ to give $1.0 \mathrm{~m} / \mathrm{s}$ sliding speed. A Mettler microbalance (accuracy $0.0001 \mathrm{~g}$ ) was used for weighing the specimens before and after the sliding. Weight loss was used as a measure of wear. The weight loss was obtained from the difference in weight of the specimen before and after the sliding test. Wear rate was calculated using weight loss per unit of sliding distance. The specimens were cleaned with acetone prior to and after the wear test. Each sliding wear test was conducted using fresh abrasive paper for a sliding distance of $1000 \mathrm{~m}$. Wear rates were calculated from weight loss measurement after every $200 \mathrm{~m}$ of sliding distance.

\section{Results and Discussion}

\subsection{Microstructure Study}

The microstructures of the substrate and overlays are shown in Fig. 2. The microstructure of steel substrate (Fig. 2(a)) shows that there are mainly two main phases in the steel i.e. ferrite and pearlite. Overlay in as welded condition exhibits dendrites of austenite near the interface (Fig. 2(b)). In the inter-dendritic region eutectic carbides are visible along the grain boundary. Constituents of eutectic are austenite and carbide. Microstructure study has shown that grains are coarser near the interface than away from interface. The amount of eutectic was found lesser near the interface as compared to the regions away from the interface in the coating. The difference in structure of coating near the interface and those at long distances away from interface is primarily due to thermal cycle experienced during welding. Heat treatment changes the microstructure of overlays significantly (Fig. (2c)). It appears that cast dendritic structure is broken down to some extent and enhances the amount of eutectic carbide. Micro-structural constituents such as martensite, chromium carbide, ferrite, tempered martensite, austenite and eutectic mixture of austenite and carbide are known to have a dominating affect on abrasive resistance of iron base alloy overlays. Overlays of similar hardness with different micro-constituents per-

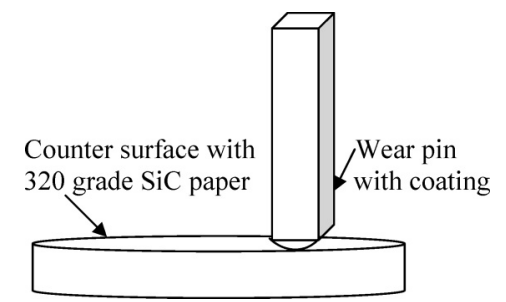

Fig. 1. Schematic diagram of wear testing set up.

(a)

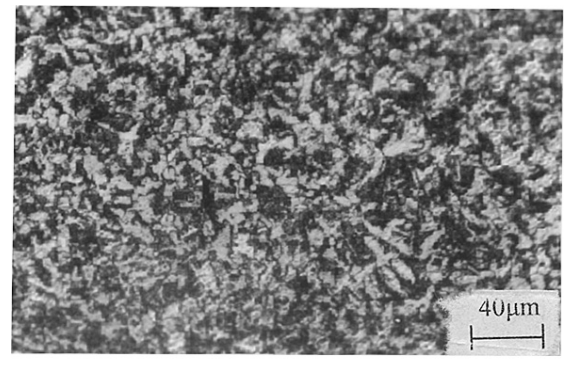

(b)

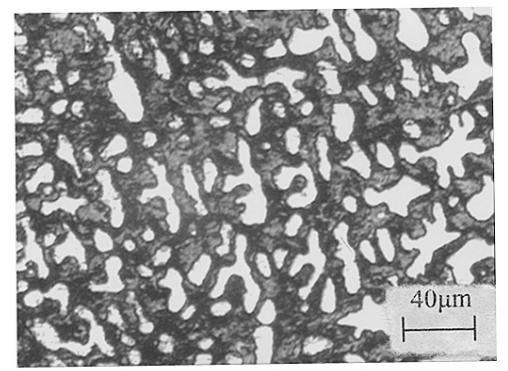

(c)

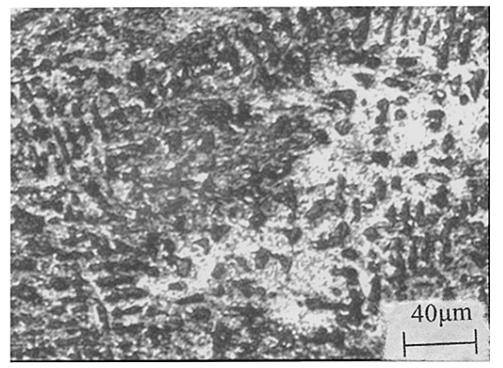

Fig. 2. Optical microphotograph of (a) steel substrate, (b) overlays in as welded condition, and (c) overlays in heat treated condition.

form in different ways. For example low alloy martensite, work hardened austenite-manganese and eutectic of austenite and carbides offer hardness of order of 50-55HRC but in low abrasive wear condition overlay with eutectic of austenite and carbide performs better than the overlays having other two types of constituents. Carbon content appreciably affects the type of micro-constituents of the overlays, therefore it is considered to be the most important element determining the abrasive wear resistance.

\subsection{Hardness Test Results}

Hardness of coating produced under different welding conditions was tested on a Rockwell hardness tester before and after heat treatment. It was observed that hardness of overlays in as welded was 58HRC. Heat treatment further enhances the hardness of overlays. The variation of hardness across the interface in as welded and heat treated conditions is shown in Fig. 3. It is observed that the hardness of overlays increases with the distance from the interface 


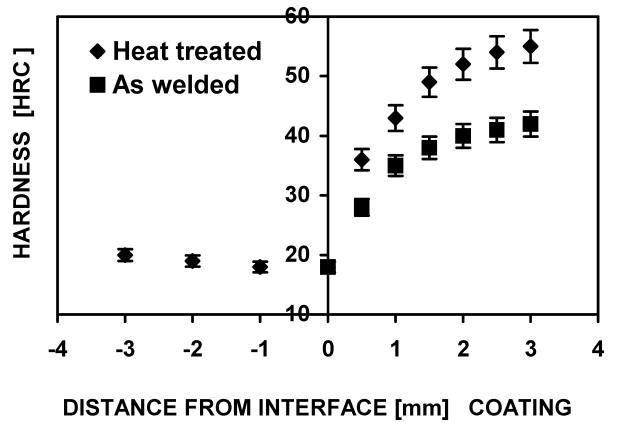

Fig. 3. Variation in hardness across the interface in as welded and heat treated conditions.

(a)

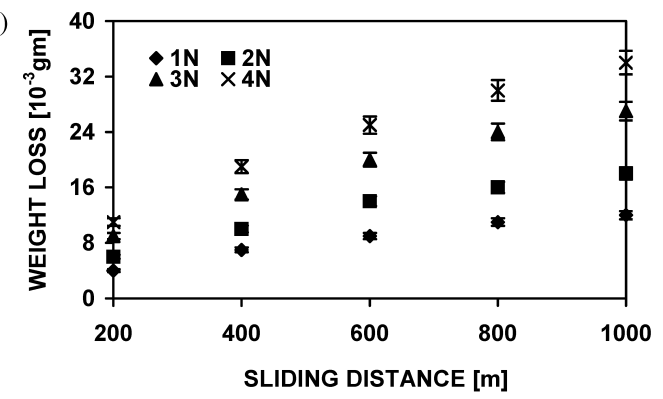

(b)

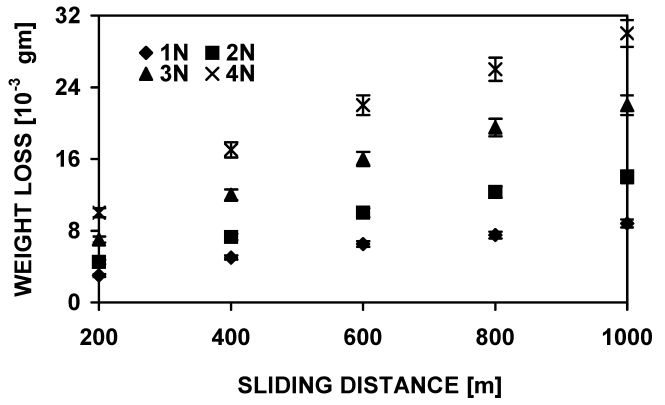

Fig. 4. Weight loss $v s$. sliding distance relationship at different normal loads in (a) as welded and (b) heat treated condition.

in the coating. It is primarily attributed to the dilution. Dilution results in an overlay having the composition different from that of electrodes due to mixing of molten base metal with electrode material during the welding.

\subsection{Wear Behaviour}

The wear behaviour of overlays (weight loss $v s$. sliding distance) at different normal loads in as welded and heat treated condition is shown in Fig. 4. It can be seen that the weight loss of overlays in as welded condition increases with increase in sliding distance irrespective of normal load (Fig. 4(a)). Increase in normal load simply increases the weight loss under identical sliding conditions. Increase in normal load also increases the depth of scoring abrasive marks from $1.1 \mu \mathrm{m}$ at $1 \mathrm{~N}$ load to $3.2 \mu \mathrm{m}$ at $4 \mathrm{~N}$ load (Table 2). Wear behaviour of overlays produced under different welding conditions after the heat treatment exhibits the trends similar to those in as welded condition (Fig. (4b)). Heat treatment reduces the weight loss under identical conditions. Figure 5 shows wear rate $v s$. normal load relationship for overlays in as welded and heat treated condition. It can be seen that increase in normal load increases the wear rate while heat treatment reduces the wear rate. Heat treatment of coating may cause the secondary hardening due to
Table 2. Average depth of groves scoring marks $(\mu \mathrm{m})$ on wear surface after sliding.

\begin{tabular}{|c|c|c|}
\hline $\begin{array}{c}\text { Normal } \\
\text { Load }(\mathrm{N})\end{array}$ & $\begin{array}{c}\text { As welded } \\
\text { overlay }\end{array}$ & $\begin{array}{c}\text { Heat treated } \\
\text { overlay }\end{array}$ \\
\hline 1 & 1.1 & 0.8 \\
\hline 2 & 1.9 & 1.3 \\
\hline 3 & 2.3 & 1.7 \\
\hline 4 & 3.2 & 2.3 \\
\hline
\end{tabular}

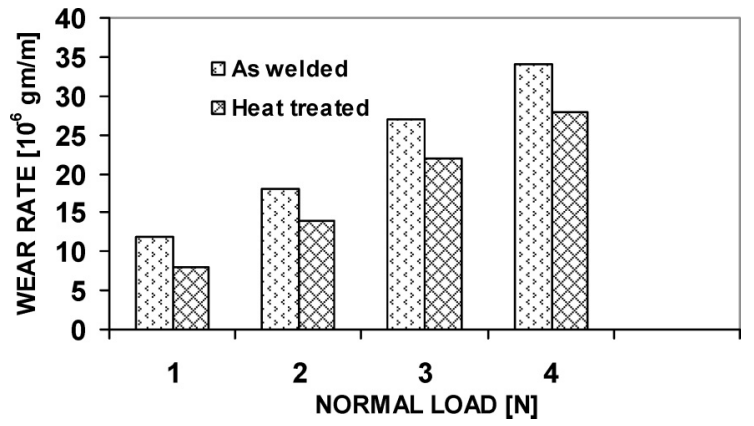

Fig. 5. Wear rate $v s$. normal load relation for the overlays in as welded and heat-treated condition.

(a)

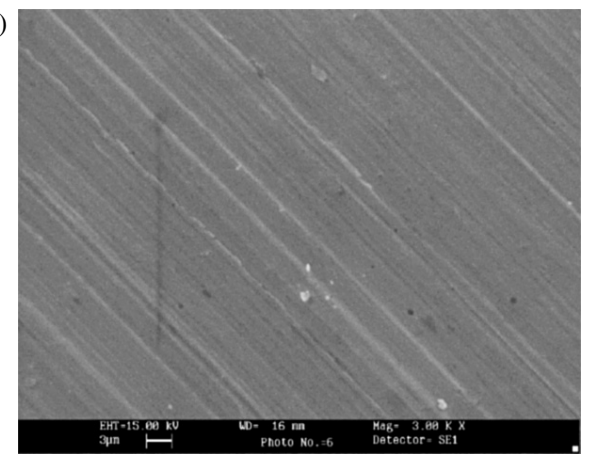

(b)

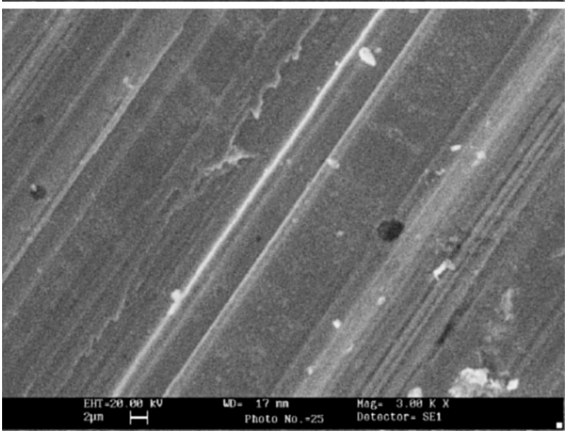

Fig. 6. SEM images of wear surface of overlays after sliding at $2 \mathrm{~N}$ in (a) as welded and (b) heat treated condition.

the precipitation of fine chromium carbide carbides. It would therefore not be wrong to speculate that increased hardness would reduce the extent of indentation necessary for abrasion and at the same time improved toughness would reduce the micro-cracking and crack propagation tendency. ${ }^{5)}$

\subsection{SEM Study of Wear Surface}

The worn surfaces of wear pins after completing the sliding tests were studied under SEM to explain the mechanism responsible for material removal under abrasive wear conditions (Fig. 6). SEM images of wear surface show the uninterrupted continuously running abrasive scoring marks. 
These indicate that there are no primary hard carbide particles in matrix and comprising mainly soft phases which can be easily abraded by the abrasive particles. The depth of the grooves as measured using a surface roughness tester (Mitutoyo SJ-301) has shown that the depth of abrasion marks increases with increase in load. In as welded condition, surface damage is primarily due to scoring and ploughing (Fig. 6(a)). Wear surface posses more number of deeper grooves per unit area in as welded condition than those in heat treated condition (Table. 2). Deeper grooves larger in number per unit area in as welded condition cause more material loss which in turn leads to higher wear rates. Heat treatment of coating reduces the depth of penetration and extent of damage on sliding surface (Fig. (6b)) and therefore, volume of material removed under identical sliding conditions is reduced.

The abrasive wear behaviour of materials is largely governed by material parameters in addition to the sliding conditions i.e. normal load, and sliding distance. ${ }^{14,16)}$ Material under abrasive wear conditions is primarily removed by ploughing and micro-cutting (Fig. 6) and both these mechanisms need penetration of materials by hard abrasive particles which in turn is controlled by the hardness of material. So, hardness of overlays plays a significant role in controlling the wear during the sliding. Increase in load also increases the penetration (Table. 2) and therefore the depth of abrasive scoring marks also increases, which in turn increases wear rate. ${ }^{17-20)}$ An increase in sliding distance increases weight loss due to more micro-fracturing and micro-cutting. Under low load condition, abrasives may cause only elastic deformation at the surface, which would produce only a minor scratching action. Sliding surface supports the low load without contributing to material removal significantly. Therefore, wear rate is less at low loads as compared to that at higher loads. Another major factor in abrasive wear is micro-cutting. ${ }^{17,18,21,22)}$ Material loss due to micro-cutting is equal to the volume of the wear groove produced. But at higher loads and longer sliding distances continuous and simultaneous action, causes material removal even through microploughing. Abrasive particles are able to effectively cut through the various phases which in turn produce uninterrupted grooves ${ }^{20,21)}$.

Microstructural parameters such as amount of primary and secondary carbides, tempered or untempered martensite, retained austenite and internal notches are important factors which should be considered in the analysis of wear behaviour of these overlays. ${ }^{4)}$ Phases of iron base alloys systems phases such as austenite, chromium carbide, eutectic of austenite-carbide and martensite have major affect on the abrasive wear. The most abrasion resistant phase in these alloys is primary carbide with austenite-carbide eutectic. The second most abrasion resistant phase in these alloys is near eutectic austenite carbide. ${ }^{4,6)}$ Improvement in wear resistance of the overlays after heat treatment is attributed to an increased proportion of hard phases due to secondary hardening. Dilution may reduce the amount of eutectic carbides and primary carbide which in turn adversely affects the wear resistance. Therefore, dilution can be attributed to variation in hardness of the coating across the interface (Fig. 3). Dilution changes the composition of overlays and hence its microstructure. Intermixing of low carbon steel with electrode material during welding would reduce the actual percentage of carbon and alloying elements in overlays. Reduction in the alloying element may decrease the hardenability, and increase the amount of soft phases which in turn will adversely affect the wear-resistance. ${ }^{22)} \mathrm{Im}$ provement in wear resistance after heat treatment may be attributed to two factors 1) the precipitation of fine carbide during the heat treatment and 2) the increased bonding of the carbide particles with the matrix. Jha et al. ${ }^{12)}$ also concluded that with low carbon and high chromium contents better wear resistance can be obtained than the combination consisting of more carbon but less chromium. Chatterjee et $a l{ }^{11)}$ reported that carbon content is an important factor determining the microstructure of such hardfacing electrodes and therefore predominantly affecting their wear-resistance. Abrasive wear resistance is not simply related to the hardness of the deposit but is determined by the carbides and matrix structure of the deposits.

\section{Summary}

(1) As welded structure shows the dendrites of austenite in matrix of eutectic. Eutectic posses a mixture of carbides and austenite. Post welded heat treatment changes the microstructure.

(2) Post weld heat treatment of overlays reduces the wear rate. Increasing normal load increases the rate of wear. The influence of dilution decreases with post weld heat treatment.

(3) The hardness of overlays varies across the interface. Heat treatment increases the hardness of overlays, but still the variation across the interface is significant.

\section{REFERENCES}

1) ASM Handbook: Welding Brazing and Soldering, 6, ASM, Ohio, (1989), 21.

2) P. K. Ghosh, O. P. Kaushal and S. K. Sharma: ISIJ Int., 32 (1992), 250.

3) J. A. Francis: Sci. Technol. Weld. Join., 7 (2002) 331.

4) D. J. Kotecki and J. S. Ogborn: Weld. J., 74 (1995), August, 269s.

5) S. J. Bull: Wear, 233-235 (1999), 412.

6) H. Berns and A. Fischer: Mater. Charact., 39 (1997), 499.

7) C. K. Kim, S. Lee, J. Y. Jung and S. Ahn: Mater. Sci. Eng. A, 349A (2003), 1.

8) K. Lee, S. H. Lee, Y. Kim, H. S. Hong, Y. M. Oh and S. J. Kim: Wear, 255 (2003), 481.

9) K. H. Gahr: Wear, 64 (1980), 175.

10) R. Dasgupta, R. Thakur, M. S. Yadav and A. K. Jha: Wear, 236 (1999), 368.

11) S. Chatterjee and T. K. Pal: Wear, 255 (2003), 417.

12) A. K. Jha, K. Prasad, R. Dasgupta, M. Singh, A. H Yegneswaran: $J$. Mater. Eng. Perform., 8 (1999), 190.

13) A. K. Jha, A. Gachake, B. K. Prasad, R. Dasgupta, M. Singh, A. H Yegneswaran: J. Mater. Eng. Perform., 11 (2002), 37.

14) R. Colaco and R. Vilar: Wear, 255 (2003), 643.

15) J. H. Yang: Weld. J., 74 (1995), 103s.

16) R. Menon: Weld. J., 75 (1996), 46.

17) R. Dasgupta, B. K. Prasad, A. K. Jha and O. P. Modi: Mater. Trans., JIM, 39 (1998), 1191.

18) S. Kumar, D. P. Mondal, H. K. Khaira and A. K. Jha: J. Mater. Eng. Perform., 8 (1999), 711.

19) E. Rabinowitcz: Friction: Wear and Lubrication, John Willy \& Sons, New York, (1965), 113

20) P. Blaskovic, N. A. Grinberg and J. Suchanek: Proc. of the Int. Welding Conf. (IWC '99) on Welding and Allied TechnologyChallenges in 21 st Century, Indian Institute of Welding, New Delhi, (1999), 406.

21) R. Dasgupta., B. K. Prasad, A. K. Jha, O. P. Modi, S. Das and A. H. Yegneswaran: Wear, 209 (1997), 255.

22) D. K. Dwivedi: Mater. Sci. Technol., 20 (2004), 1326. 